\title{
Design and Simulation of Space Vector PWM for Three-Phase Induction Motor
}

\author{
Pradeep. H. Yakkundi ${ }^{1}$, K. V. Devadas ${ }^{2}$ and K.Suryasen ${ }^{3}$ \\ $\left({ }^{1}\right.$ P.G.Scholar,Departement of Electrical and Electronics Engineering,K.V.G.College of Engineering,Sullia, DK, \\ Karnataka, India) \\ $\left({ }^{2}\right.$ Professor and Head, Departement of Electrical and Electronics Engineering, K.V.G.College of Engineering, \\ Sullia, DK, Karnataka, India) \\ $\left(^{3}\right.$ Assistant Professor, Departement of Electrical and Electronics Engineering,K.V.G.College of Engineering, \\ Sullia, DK, Karnataka, India)
}

\begin{abstract}
In this Work, Space Vector Modulation (SVM) will be utilized as another alternative modulation technique which was known to be better than SPWM techniques in certain areas. Space Vector Pulse Width Modulation (SVPWM) has become the successful techniques to construct three phase sine wave Voltage Source Inverter (VSI) parallel to control three-phase motor using vector control method. The VSI have six legs for the three-phase induction motor, and eight switching sequences had been simulated in MATLAB / SIMULINK. The simulation result shows the feasibility of the proposed modulation techniques to drive three-phase induction motor.
\end{abstract}

Keywords: Induction Machine, Pulse width modulation (PWM), Sinusoidal PWM, Space Vector PWM, Voltage Source Inverter.

\section{Introduction:}

The inverters are used to converts dc power into ac power at desired output voltage and frequency. The waveform of the output voltage depends on the switching states of the switches used in the inverter. Major limitations and requirements of inverters are harmonic contents, the switching frequency, and the best utilization of dc link voltage. Pulse width modulation (PWM) inverters are studied extensively during the past decades. In this method, a fixed dc input voltage is given to the inverter and a controlled ac output voltage is obtained by adjusting the on and off periods of the inverter components. The most popular PWM techniques are the sinusoidal PWM and space Vector PWM. With the development of DSPs, space-vector modulation (SVM) has become one of the most important PWM methods for three-phase voltage source inverters. In this technique, Space-vector concept is used to compute the duty cycle of the switches. It is simply the digital implementation of PWM modulators. Most advanced features of SVM are easy digital implementation and wide linear modulation range for output line-to-line voltages.

\subsection{Three-Phase AC Induction Motor Control Principle}

The 3-phase stators and 3-phase rotors are considered as two fundamental parts of a 3-phase AC induction motor. When the 3-phase stators are energized by the 3-phase AC power source, current flow is generated in the stators. The magnetic field synthesized by 3-phase stator current is always rotating incessantly with the variation of the current. This rotating magnetic field cuts the rotor and the current generated in it interacts with the rotating magnetic field and thus produces the magnetic torque which makes the rotor rotate (Figure 1). The rotating speed of the rotor $n$ should be less than that of the rotating magnetic field $n 0$. Reverse rotating of the rotor will be realized by two of the 3 -phase power source positions exchanged.

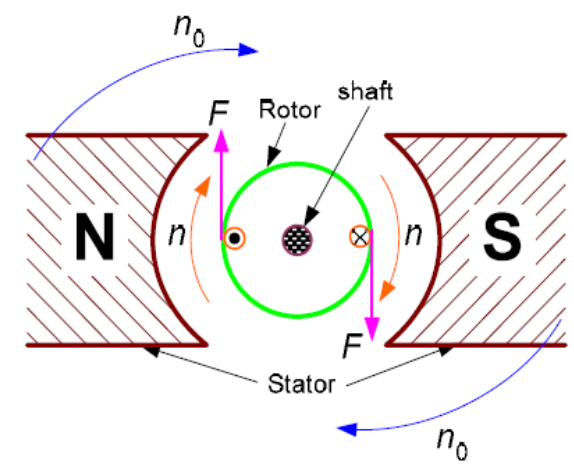


Figure 1: rotating start for AC induction motor

The rotating direction of the rotating magnetic field is consistent with the current phase and its speed is proportional to the power source frequency $\mathrm{f}$ and inversely proportional to the magnetic polar pair number $\mathrm{P}$. Calculated per minute, the speed of the rotating magnetic field $\mathrm{n}_{0}$ can be represented by this equation:

$$
\mathrm{n}_{\mathrm{o}}=60 / \mathrm{p}
$$

\subsection{VVVF Control:}

From the equation (1) two primary methods for speed control of 3-phase AC induction motor can be concluded: one is to change the magnetic polar pair numbers but the inflexibility and low efficiency of this method has limited its popularity of application. Another method is to regulate the stator current frequency. Usually a principle of popular practical implementation called "variable voltage variable frequency" (VVVF) is adopted on speed regulation. The 3-phase stators cutting the flux of the rotating magnetic field results in the back Electromotive force generated and it can be calculated by the equation given below

$$
\mathrm{E}_{1}=4.44 \mathrm{~K}_{\mathrm{r} 1} \mathrm{f}_{1} \mathrm{~N}_{1} \phi_{\mathrm{M}}
$$

Where $k \mathrm{r} 1$ is the winding structure related constant and $N 1$ is the number of turns of the stator winding per phase, $f 1$ is the stator current frequency, $\Phi_{\mathrm{M}}$ is the main flux. Let a constant $K_{E l=} 4.44 \mathrm{k}_{\mathrm{R} 1} \mathrm{~N}_{1}$, we have

$$
\mathrm{E}_{1}=\mathrm{K}_{\mathrm{E} 1} \mathrm{f}_{1} \Phi_{\mathrm{M}}
$$

Since the voltage drop on the stators impedance only occupies relatively very small portion of the whole stator voltage $U 1$ and can be ignored, therefore

Derived From (3) and (4), it holds

$$
\mathrm{U}_{1} \approx \mathrm{E}_{1}
$$

$$
\Phi_{\mathrm{M}}=\mathrm{K}_{\Phi} \mathbf{U}_{1 /} \mathrm{F}_{1}
$$

Where $\mathrm{K}_{\Phi}=1 / \mathrm{K}_{\mathrm{E} 1}$ is also a constant. From (5) it can be concluded that if the value of $\mathrm{U}_{1} / \mathrm{f}_{1}$ can be controlled to be a constant, $\Phi M$ remains unchanged. This control method to regulate frequency with voltage changed accordingly is usually called "VVVF", i.e. Variable Voltage Variable Frequency.

\section{Pulse Width Modulation}

PWM inverters are gradually taking over other types of inverters in industrial applications.PWM techniques are characterized by constant amplitude pulses. The width of these pulses is, however modulated to obtain inverter output voltage control and to reduce its harmonic content.

\subsection{Sinusoidal PWM Concept}

The sinusoidal pulse-width modulation (SPWM) technique produces a sinusoidal waveform by filtering an output pulse waveform with varying width. A high switching frequency leads to a better filtered sinusoidal output waveform. The desired output voltage is achieved by varying the frequency and amplitude of a reference or modulating voltage. The variations in the amplitude and frequency of the reference voltage change the pulsewidth patterns of the output voltage but keep the sinusoidal modulation. As shown in, a low-frequency sinusoidal modulating waveform is compared with a high-frequency triangular waveform, which is called the carrier waveform. The switching state is changed when the sine waveform intersects the triangular waveform. The crossing positions determine the variable switching times between states. In three-phase SPWM, a triangular voltage waveform (VT ) is compared with three sinusoidal control voltages ( $\mathrm{Va}, \mathrm{Vb}$, and $\mathrm{Vc}$ ), which are $120^{\circ}$ out of phase with each other and the relative levels of the waveforms are used to control the switching of the devices in each phase leg of the inverter. A six-step inverter is composed of six switches S1 through S6 with each phase output connected to the middle of each inverter leg as shown in. The output of the comparators forms the control signals for the three legs of the inverter. Two switches in each phase make up one leg and open and close in a complementary fashion. That is, when one switch is open, the other is closed and vice-versa. The output pole voltages Vao, Vbo, and Vco of the inverter switch between $-\mathrm{Vdc} / 2$ and $+\mathrm{Vdc} / 2$ voltage levels where Vdc is the total DC voltage.

The peak of the sine modulating waveform is always less than the peak of the triangle carrier voltage waveform. When the sinusoidal waveform is greater than the triangular waveform, the upper switch is turned on and the lower switch is turned off. Similarly, when the sinusoidal waveform is less than the triangular waveform, the upper switch is off and the lower switch is on. Depending on the switching states, either the positive or negative half DC bus voltage is applied to each phase. The switches are controlled in pairs $((\mathrm{S} 1 ; \mathrm{S} 4)$, $(\mathrm{S} 3 ; \mathrm{S} 6)$, and $(\mathrm{S} 5 ; \mathrm{S} 2))$ and the logic for the switch control signals is: 


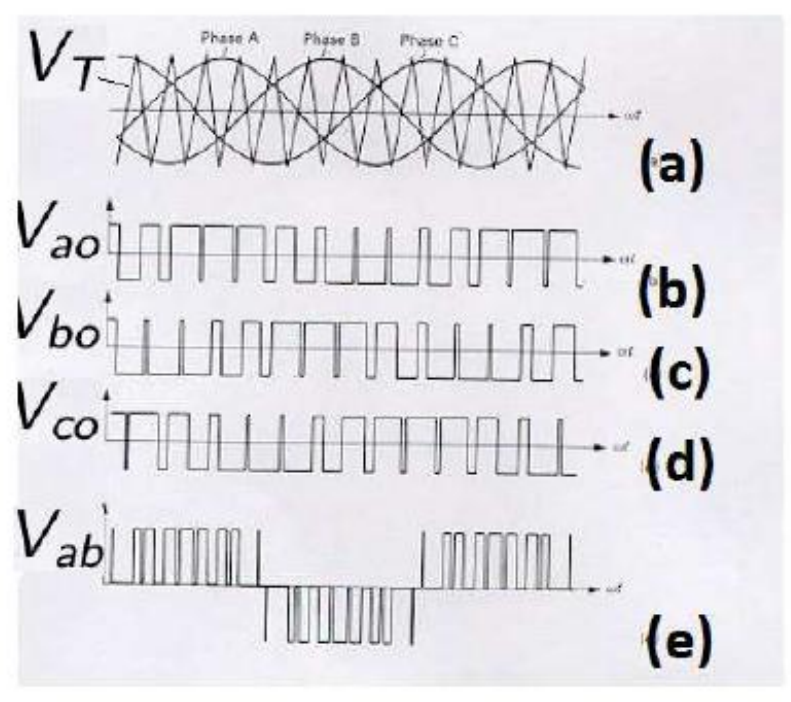

Fig.2: pwm waveforms

\subsection{Space Vector PWM (SVPWM)}

SV-PWM is just a modulation algorithm which translates phase voltage (phase to neutral) references, coming from the controller, into modulation times/duty-cycles to be applied to the PWM peripheral. It is a general technique for any three-phase load, although it has been developed for motor control. SV-PWM maximizes DC bus voltage exploitation and uses the "nearest" vectors, which translates into a minimization of the harmonic content. The classical application of SV-PWM is vector motor control, which is based on the control of currents' projection on two orthogonal coordinates (direct and quadrature, $\mathrm{d}_{\mathrm{q}}$ ), called Field Oriented Control (FOC). For induction machines, the most common choices for the direct axis is to align it to the rotor field (rotor FOC) or to the stator field (stator FOC).

The basic concept is that with a known motor and known voltage output pulses we can accurately determine rotor slip by monitoring current and phase shift. The controller can then modify the PWM "sine" wave shape, frequency or amplitude to achieve the desired result. For example the desired speed is $200 \mathrm{rpm}$ and the control senses there is $2 \mathrm{rpm}$ of slip so it increases the frequency slightly to bring the speed up. Since torque can also be determined, it can also be controlled. SVPWM just does a lot of sampling, calculating and wave form manipulation. The specific algorithms and deciding what the best output solution is for different situations could fill up several books. SV means space vector, as in space vector modulation. SVM basically allows a 3phase bridge PWM drive to supply about $15 \%$ higher peak voltage to a motor than the standard sine-triangle modulation scheme by allowing the neutral point of the motor to move away from the nominal $1 / 2$ of the supply rail. The Space Vector Pulse Width Modulation (SVPWM) refers to a special switching sequence of the upper three power devices of a three-phase voltage source inverters (VSI) used in application such as AC induction and permanent magnet synchronous motor drives. It is a more sophisticated technique for generating sine wave that provides a higher voltage to the motor with lower total harmonic distortion. Space Vector PWM (SVPWM) method is an advanced; computation intensive PWM method and possibly the best techniques for variable frequency drive application. In SVPWM technique, instead of using a separate modulator for each of the three phases, the complex reference voltage vector is processed as a whole. Therefore, the interaction between the three motor phases is considered. SVPWM generates less harmonic distortion in the output voltages and currents in the windings of the motor load and provides a more efficient use of the DC supply voltage in comparison with sinusoidal modulation techniques. Since SVPWM provides a constant switching frequency; the switching frequency can be adjusted easily. Although SVPWM is more complicated than sinusoidal PWM, it may be implemented easily with modern DSP based control systems.

\subsection{Principle of Space Vector PWM}

A three-phase mathematical system can be represented by a space vector. For example, given a set of three-phase voltages, a space vector can be defined by

$$
\begin{aligned}
\mathrm{Va} & =\mathrm{Vm} \sin \omega \mathrm{t} \\
\mathrm{Vb} & =\mathrm{Vm} \sin \left(\omega \mathrm{t}-120^{\circ}\right) \\
\mathrm{Vc} & =\mathrm{Vm} \sin \left(\omega \mathrm{t}+120^{\circ}\right)
\end{aligned}
$$


Where $\mathrm{Va}(\mathrm{t}), \mathrm{Vb}(\mathrm{t})$, and $\mathrm{Vc}(\mathrm{t})$ are three sinusoidal voltages of the same amplitude and frequency but with $120^{\circ}$ phase shifts. The space vector at any given time maintains its magnitude. As time increases, the angle of the space vector increases, causing the vector to rotate with a frequency equal to that of the sinusoidal waveforms. When the output voltages of a three-phase six-step inverter are converted to a space vector and plotted on the complex plane, the corresponding space vector takes only on one of six discrete angles as time increases. The central idea of SVWPM is to generate appropriate PWM signals so that a vector with any desired angle can be generated. SVPWM is a form of PWM proposed in the mid-1980s that is more efficient compared to natural and regularly-sampled PWM. In the space-vector modulation, a three-phase two-level inverter can be driven to eight switching states where the inverter has six active states (1-6) and two zero states (0 and 7). A typical two-level inverter has 6 power switches (labeled S1 to S6) that generate three-phase voltage outputs. The circuit has a full-bridge topology with three inverter legs, each consisting of two power switches. The circuit allows only positive power flow from the supply system to the load via a full-bridge diode rectifier. Negative power flow is not possible through the rectifier diode bridge. The six switching power devices can be constructed using power BJTs, GTOs, IGBTs, etc. The choice of switching devices is based on the desired operating power level, required switching frequency, and acceptable inverter power losses. When an upper transistor is switched on, the corresponding lower transistor is switched off. Therefore, the ON and OFF states of the upper transistors $\mathrm{S} 1 ; \mathrm{S} 3$;S5 can be used to determine the current output voltage. The ON and OFF states of the lower power devices are complementary to the upper ones. Two switches on the same leg cannot be closed or opened at the same time.

The basic principle of SVPWM is based on the eight switch combinations of three phase inverter. The switch combinations can be represented as binary codes that correspond to the top switches S1, S3, and S5 of the inverter. Each switching circuit generates three independent pole voltages Vao, Vbo, and Vco.

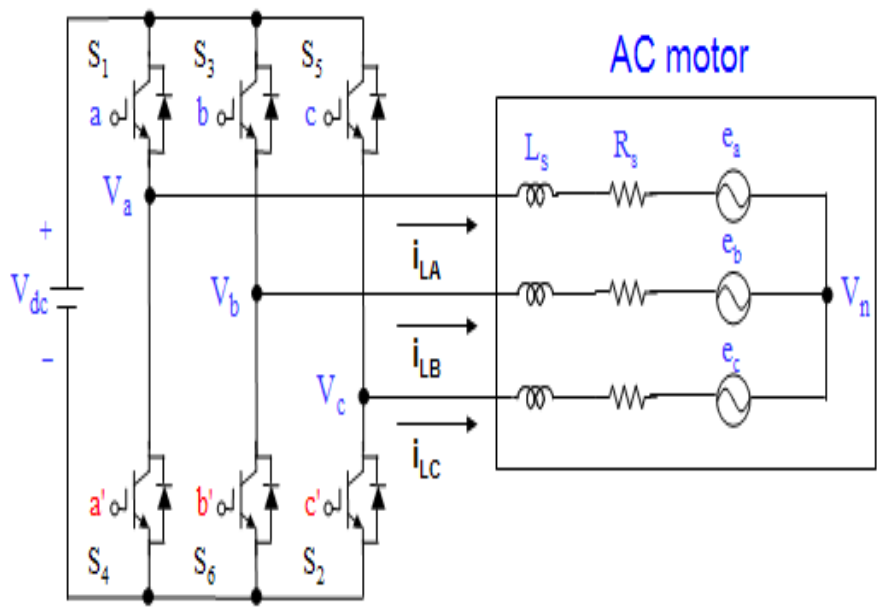

Fig.3: three-phase voltage source pwm Inverter

Consider three phase waveforms which are displaced by $120^{\circ}$, as mentioned in equation (1),(2),(3).

These three vectors can be represented by a one vector which is known as space vector. Space vector is defined as,

$V_{s}=V_{a}+V_{b} e^{j 2 \pi / 3}+V_{c} e^{-j 2 \pi / 3}$

$\mathrm{Vs}=3 / 2 \mathrm{Vm}[\sin \omega \mathrm{t}-\mathrm{j} \cos \omega \mathrm{t}]$

Space vector can represented as;

$$
\begin{gathered}
\mathrm{Vs}_{\mathrm{s}}=\mathrm{Vd}+\mathrm{j} \mathrm{Vq} \\
\theta=\tan -1\left(\mathrm{~V}_{\mathrm{q}} / \mathrm{V}_{\mathrm{d}}\right) \\
{\left[\begin{array}{c}
\mathrm{V}_{\mathrm{d}} \\
\mathrm{V}_{\mathrm{q}}
\end{array}\right]=\left[\begin{array}{rrr}
1 & -\frac{1}{2} & -\frac{1}{2} \\
0 & \frac{\sqrt{3}}{2} & -\frac{\sqrt{3}}{2}
\end{array}\right]\left[\begin{array}{c}
\mathrm{V}_{\mathrm{a}} \\
\mathrm{V}_{\mathrm{b}} \\
\mathrm{V}_{\mathrm{c}}
\end{array}\right]}
\end{gathered}
$$


Also, the relationship between the switching variable vector $[\mathrm{a}, \mathrm{b}, \mathrm{c}] \mathrm{t}$ and the phase voltage vector $[\mathrm{VaVbVc}]^{\mathrm{t}}$ can be expressed below.

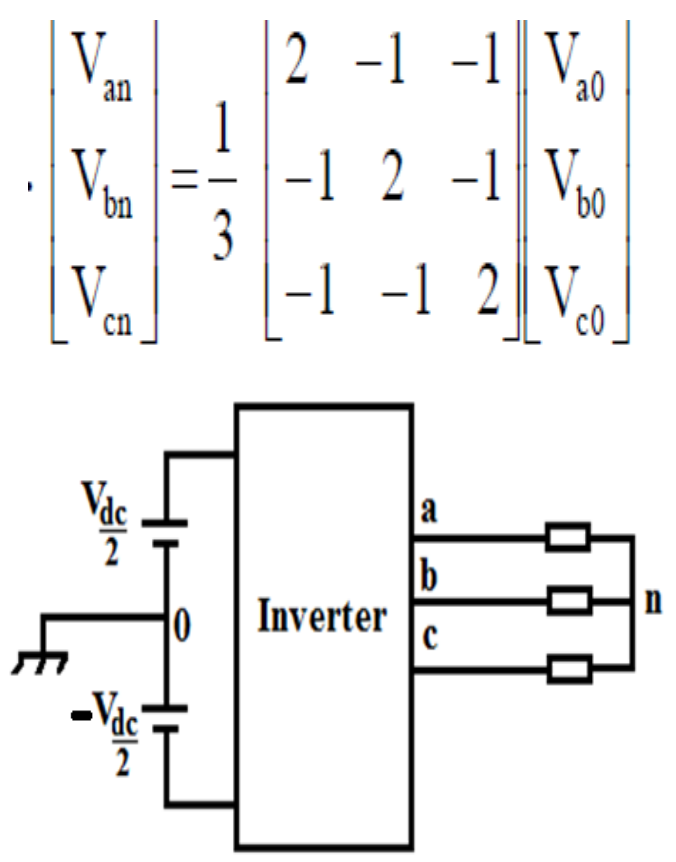

Fig.4: inverter fed star connected load

\subsection{Realization Of Space Vector Pwm}

$\mathrm{V}_{\mathrm{d}}$ - daxis voltage

$\mathrm{V}_{\mathrm{q}}$-quarture axis

$\mathrm{V}_{\text {ref }}$ - reference voltage

i) Determine $V_{d}, V_{q}, V_{\text {ref }}$ and angle $(\alpha)$ :

$\mathrm{V}_{\mathrm{d}}=\mathrm{V}_{\mathrm{an}}-1 / 2 \mathrm{~V}_{\mathrm{bn}}-1 / 2 \mathrm{~V}_{\mathrm{cn}}$

$\mathrm{Vq}=\mathrm{Van}+\operatorname{sqrt}(3) / 2 \mathrm{Vbn}-\operatorname{sqrt}(3) / 2$

$\mid$ Vref $\left.\left.\right|_{=}{\sqrt{\left(V_{\mathrm{d}}\right.}}^{2}+\mathrm{V}_{\mathrm{q}}^{2}\right)$

$\mathrm{T}_{1=} \sqrt{3} \mathrm{t}_{\mathrm{z}} \mid$ Vref $\mid / \mathrm{V}_{\mathrm{dc}} \sin \theta[(\mathrm{n} / 3) \pi \cos \alpha-\cos (\mathrm{n} / 3) \pi \sin \alpha]$

$\mathrm{T}_{2}=\sqrt{3} \mathrm{t}_{\mathrm{z}}|\operatorname{Vref}| / \mathrm{V}_{\mathrm{dc}} \sin \theta[-\cos \alpha \sin (\mathrm{n}-1 / 3) \pi+\sin \alpha \cos (\mathrm{n}-1 / 3 \pi)]$

The reference voltage vector Vref rotates in space at an angular velocity $w=2 \pi f$, where $f$ is the fundamental frequency of the inverter output voltage. When the reference voltage vector passes through each sector, different sets of switches turned on or off. As a result, when the reference voltage vector rotates through one revolution in space, the inverter output varies one electrical cycle over time. The inverter output frequency coincides with the rotating speed of the reference voltage vector. The zero vectors (V0 and V7) and active vectors (V1 to V6) do not move in space. They are referred to as stationary vectors. Fig.5 shows the reference vector Vref in the first sector. The six active voltage space vectors are shown on the same graph with an equal magnitude of $2 \mathrm{Vdc}$ in third sector and a phase displacement of $60^{\circ}$. The inverter cannot produce a desired reference voltage vector directly. It is possible to decompose the reference vector into vectors that lie on two adjacent active vectors and two zero vectors, which are located at the center of hexagon. 


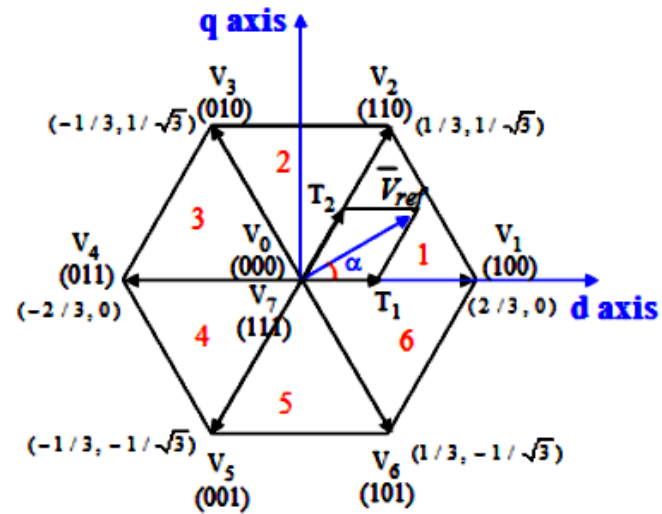

Fig5.Six Sector Switching Pattern

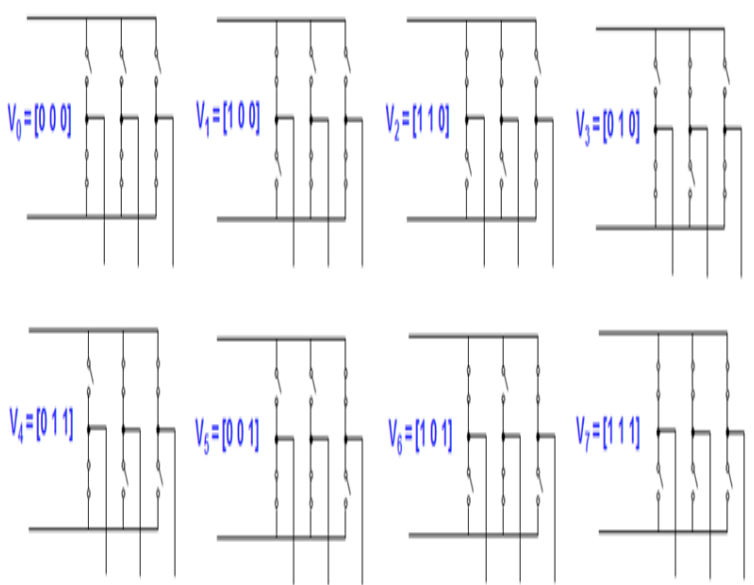

Fig6. Eight Inverter Voltage Vectors (V0 to V7

\begin{tabular}{|c|c|c|}
\hline SECTOR & UPPER SWITCHIG & LOWER SWITCHING \\
\hline $\mathbf{S}_{1}$ & $\begin{array}{l}\mathrm{S} 1=\mathrm{T} 1+\mathrm{T} 2+\mathrm{T} 0 / 2 \\
\mathrm{~S} 3=\mathrm{T} 2+\mathrm{T} 0 / 2 \\
\mathrm{~S} 5=\mathrm{T} 0 / 5\end{array}$ & $\begin{array}{l}\mathrm{S} 4=\mathrm{T} 0 / 2 \\
\mathrm{~S} 6=\mathrm{T} 1+\mathrm{T} 0 / 2 \\
\mathrm{~S} 2=\mathrm{T} 1+\mathrm{T} 2+\mathrm{T} 0 / 2\end{array}$ \\
\hline $\mathbf{S}_{2}$ & $\begin{array}{l}\mathrm{S} 1=\mathrm{T} 1+\mathrm{T} 0 / 2 \\
\mathrm{~S} 3=\mathrm{T} 1+\mathrm{T} 2+\mathrm{T} 0 / 2 \\
\mathrm{~S} 5=\mathrm{T} 0 / 2\end{array}$ & $\begin{array}{l}\mathrm{S} 4=\mathrm{T} 2+\mathrm{T} 0 / 2 \\
\mathrm{~S} 6=\mathrm{T} 0 / 2 \\
\mathrm{~S} 2=\mathrm{T} 1+\mathrm{T} 2+\mathrm{T} 0 / 2\end{array}$ \\
\hline $\mathbf{S}_{3}$ & $\begin{array}{l}\mathrm{S} 1=\mathrm{T} 0 / 2 \\
\mathrm{~S} 3=\mathrm{T} 1+\mathrm{T} 2+\mathrm{T} 0 / 2 \\
\mathrm{~S} 5=\mathrm{T} 2+\mathrm{T} 0 / 5\end{array}$ & $\begin{array}{l}\mathrm{S} 4=\mathrm{T} 1+\mathrm{T} 2+\mathrm{T} 0 / 2 \\
\mathrm{~S} 6=\mathrm{T} 0 / 2 \\
\mathrm{~S} 2=\mathrm{T} 2+\mathrm{T} 0 / 2\end{array}$ \\
\hline $\mathbf{S}_{4}$ & $\begin{array}{l}\mathrm{S} 1=\mathrm{T} 0 / 2 \\
\mathrm{~S} 3=\mathrm{T} 1+\mathrm{T} 0 / 2 \\
\mathrm{~S} 5=\mathrm{T} 1+\mathrm{T} 2+\mathrm{T} 0 / 2\end{array}$ & $\begin{array}{l}\mathrm{S} 4=\mathrm{T} 1+\mathrm{T} 2+\mathrm{T} 0 / 2 \\
\mathrm{~S} 6=\mathrm{T} 0 / 2 \\
\mathrm{~S} 2=\mathrm{T} 0 / 2\end{array}$ \\
\hline $\mathbf{S}_{5}$ & $\begin{array}{l}\mathrm{S} 1=\mathrm{T} 2+\mathrm{T} 0 / 2 \\
\mathrm{~S} 3=\mathrm{T} 0 / 2 \\
\mathrm{~S} 5=\mathrm{T} 1+\mathrm{T} 2+\mathrm{T} 0 / 2\end{array}$ & $\begin{array}{l}\mathrm{S} 4=\mathrm{T} 1+\mathrm{T} 0 / 2 \\
\mathrm{~S} 6=\mathrm{T} 1+\mathrm{T} 2+\mathrm{T} 0 / 2 \\
\mathrm{~S} 2=\mathrm{T} 0 / 2\end{array}$ \\
\hline$S_{6}$ & $\begin{array}{l}\mathrm{S} 1=\mathrm{T} 1+\mathrm{T} 2+\mathrm{T} 0 / 2 \\
\mathrm{~S} 3=\mathrm{T} 0 / 2 \\
\mathrm{~S} 5=\mathrm{T} 1+\mathrm{T} 0 / 5\end{array}$ & $\begin{array}{l}\mathrm{S} 4=\mathrm{T} 0 / 2 \\
\mathrm{~S} 6=\mathrm{T} 1+\mathrm{T} 2+\mathrm{T} 0 / 2 \\
\mathrm{~S} 2=\mathrm{T} 2+\mathrm{T} 0 / 2\end{array}$ \\
\hline
\end{tabular}

Table1 


\section{Simulation Model:}

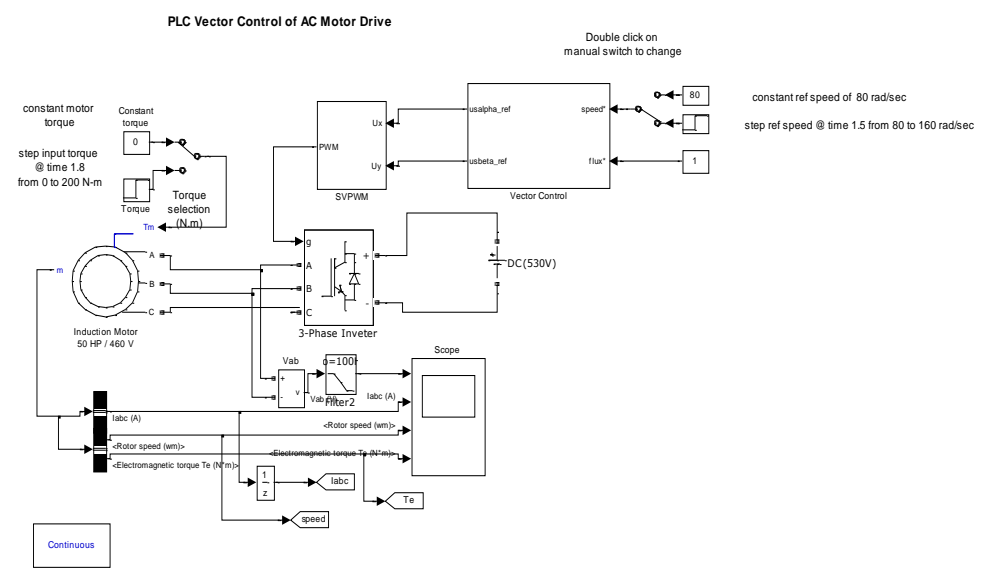

Table 2

\begin{tabular}{|c|c|}
\hline parameters & values \\
\hline Power $P_{n}$ & $37.3 \mathrm{kw}$ \\
\hline Voltage $V_{s}$ & $460 \mathrm{~V}$ \\
\hline frequency & $60 \mathrm{~Hz}$ \\
\hline Stator resistance & 0.087 ohm \\
\hline Rotor resistance & 0.228 ohm \\
\hline Stator inductance & $0.8 * 10-{ }^{3} \quad$ H \\
\hline Rotor inductance & $0.8 * 10-^{3} \quad$ H \\
\hline Mutual induction & $34.7 * 10-^{3} \quad$ H \\
\hline
\end{tabular}

IV. Results:

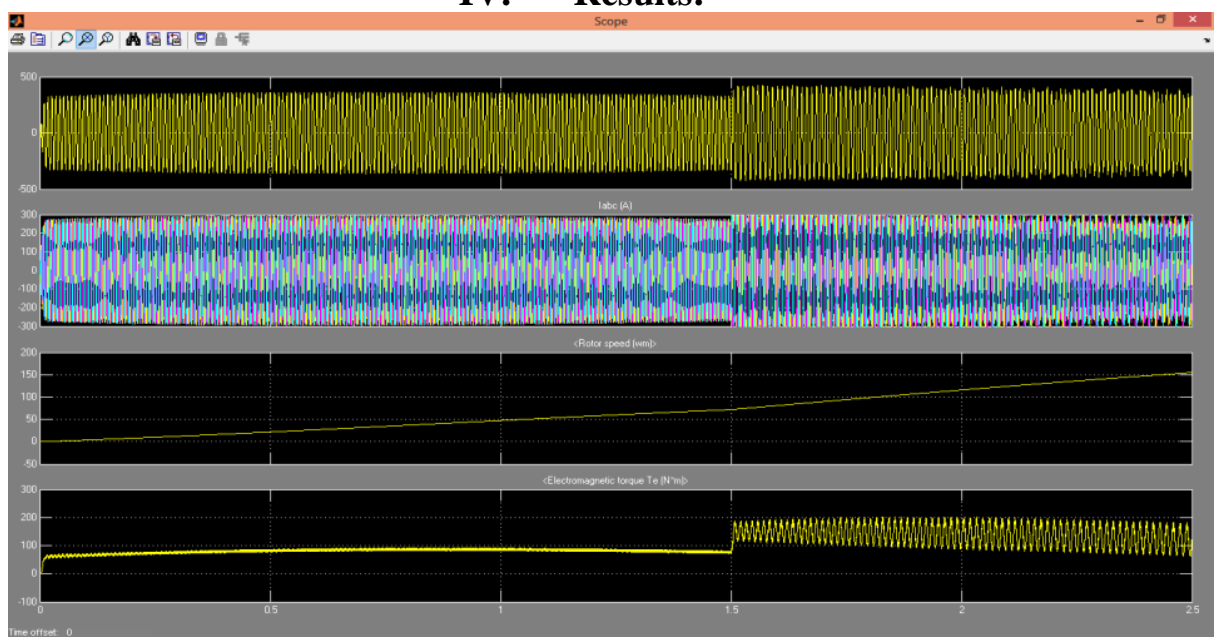

Fig shows the simulated waveforms for the output voltage, current (Iabc), rotor speed, electromagnetic torque $\mathrm{v} / \mathrm{s}$ time. We observe a step speed reference change at $1.5 \mathrm{~s}$ in waveforms.

\section{Conclusion:}

In this paper the space voltage vector pulse width modulation technique is proposed to drive threephase induction motor. Such technique is applied to adjustable speed of three-phase induction motor drives. Space vector Modulation Technique has become the most popular and important PWM technique for Three Phase Voltage Source Inverters for the control of AC Induction, Brushless DC, Switched Reluctance and Permanent Magnet Synchronous Motors. This technique actually can utilize $100 \%$ DC source since there is no center tap from the dc source, and allow index modulation greater than 1 (enable over modulation). This technique is proposed to eliminate the use of capacitor to run the motor. In case of SVPWM the output voltage 
is about $15 \%$ more as compared to SPWM. The SVPWM technique utilizes DC bus voltage more efficiently and generates less harmonic distortion in a three-phase voltage-source inverter.

\section{References}

[1] HAITHAM ABU-RUB ATLIF IQBAL JAROSLAW GUZINSKI "High performance control of AC drives with MATLAB/SIMULINK Models"

[2] Bai Hua, et al, "Comparison of ThreePWM Strategies - SPWM, SVPWM \&One-cycle Control" Power Electronics and Drive Systems, 2003. PEDS 2003.The Fifth International Conference on Volume 2, 17-20 Nov. 2003 Page(s):1313-1316 Vol.2.

[3] Wei-Feng Zhang and Yue-Hui Yu, "Comparison of Three SVPWM Strategies" Journal of Electrical Science and Technology of China, Vol. 5. No.3, September 2007. pg. $283-287$.

[4] P. C. Krause, 0. Wasynczuk, and S. D. Sudhoff, “Analysis of electric machinery”,IEEE Press, Piscataway, N.J., 1996, ISBN 07803-1 101-9, pp. $415-447$.

[5] Frede Blaabjerg, et. al, "Comparison of Variable Speed Drives for Single-Phase Induction Motors". Power Conversion Conference 2002, PCC Osaka 2002, Proceedings of the Volume 3, 2-5 April 2002 Page(s):1328-1333 vol. 3.

[6] E. R. Collins Jr., and R. E. Ashley 111,"Operating characteristics of single phase capacitor motors driven from variable frequency supplies", Proceedings of Industry Applications Society Annual Meeting, 1991, p. 52 -57, vol. 1.

[7] H. W. van der Broeck, H.C. Skudelny and G. Stanke, "Analysis and realization of a pulse width modulator based on voltage space vectors", IEEE Trans. Ind. Applicat., vol. 24, pp. 142-150, Jan. /Feb. 1988.

[8] A. Boglietti, et al, "Different PWM Modulation Techniques Indexes Performance Evaluation", in IEEE IAS 1993 Conference Record, pp. 193-199.

[9] Zhou, K. and Wang, D., "Relationship between space vector modulation and three-phase carrier-based PWM: A comprehensive analysis". IEEE Trans. Ind. Electron. 49, 186-196. 2002.

[10] P. C. Krause, "Simulation of Unsymmetrical 2-Phase Induction Machines", IEEE Transactions on Power Apparatus and Systems, vol. PAS-84, NO.

[11] MICRO-CONTROLLER BASED SPACE VECTOR MODULATION (SVM) SIGNAL GENERATOR Mr. B.Parthiban1, Mr. John Powl.S2, Mr. P.Sivaprakasam3, Mr. N.Elayaraja.

[12] B. K. Bose, "Power Electronics and Variable Frequency Drives: 39 Technology and Applications.”IEEE Press, 1997. Rashid, M. H., "Power Electronics Handbook," Academic Press, 2001.

[13] Mohan, N., "First Course on Power Electronics and Drives," MNPERE, 2003.

[14] R. Krishnan, "Electric Motor Drives Modelling, Analysis and Control", Prentice Hall, 2001.

[15] J. Holtz, "Pulse width modulation - A Survey", IEEE Transactions on Industrial Electronics, Vol. 30, No.5, Dec 1992, pp. 410-420.

[16] H. W. V. D. Brocker, H. C. Skudenly and G. Stanke, "Analysis and realization of a pulse width modulator based on the voltage space vectors," in Conf. Rec. IEEE-IAS Annu. Meeting, Denver, CO, 1986, pp. 244-251.

[17] Dorin O. Neacsu, "Space Vector Modulation-an introduction," The 27th annual conference of the IEEE industrial electronics society. 